\title{
Research on hydrogen-induced cracking behavior of normalized pipeline steel
}

\author{
Hai Zhang ${ }^{1,2, a}$, Shaopo $\mathrm{Li}^{1}$, Wenhua Ding ${ }^{1}$ and Ning Hao ${ }^{1}$ \\ ${ }^{1}$ Research Institute of Technology, Shougang Group Corporation, Beijing, 100043, China \\ ${ }^{2}$ Beijing Engineering Research Center of Energy Steel, Beijing, 100043, China
}

\begin{abstract}
Hydrogen sulfide corrosion test was used to test the hydrogen-induced cracking sensitivity of the normalized BNS pipeline steel. The microstructure and morphology of hydrogen induced crack(HIC) of the normalized BNS pipeline steel after hydrogen sulfide corrosion test were observed with optical microscopy $(\mathrm{OM})$, scanning electron microscopy(SEM). Combined with electron probe microanalyzer(EPMA) and hardness test, the hydrogen-induced cracking behavior of BNS pipeline steel was studied from the aspects of microstructure, crack morphology, center segregation and harness. The results showed that the pearlite band with high hardness caused by center segregation of $\mathrm{C}$ and $\mathrm{Mn}$ was the main crack initiation and propagation path for the long-size and linear shape hydrogen induced crack at the center of plate thickness, and the type of crack propagation was transgranular. Some tiny hydrogen induced crack nucleated from the small calcium-aluminate inclusion and the tiny hydrogen induced crack would not propagate to form long-size cracks with no suitable propagation path existing around the inclusion.
\end{abstract}

\section{Introduction}

The sustainable economic development has led to an increase in demand for oil and natural gas resources. In order to meet the demand, the scale of oil and natural gas exploitation continue to expand in China. However, some oil and natural gas contain a lot of $\mathrm{H}_{2} \mathrm{~S}$ gas. When pipeline is used to transport the oil and natural gas which are rich in $\mathrm{H}_{2} \mathrm{~S}$ gas, hydrogen induced crack is easily produced in pipeline which can cause pipeline leakage to reduce pipeline life. Therefore, the pipeline steel used in the manufacture of the pipeline was required to have high strength, excellent toughness and good HIC resistance.

So far, there have been many reports on hydrogen induced crack of pipeline stee ${ }^{[1-4]}$. And most of the reports mainly focus on hydrogen induced-cracking behavior of rolled pipeline steel produced by Thermo Mechanical Control Process(TMCP). Meanwhile there is few researches on the hydrogen induced-cracking behavior of the heat treated pipeline steel. However, taking into account the advantage of the steady state of the microstructure of pipeline steel heat treated and the complexity of service environment, some users require the pipeline steel to be used in a heat treatment state. Therefore a normalized BNS pipeline steel was investigated in this paper and hydrogen induced crack test was performed on it. Then the hydrogen inducedcracking behavior of the normalized BNS pipeline steel was studied by the analysis of the microstructure, crack morphology, and the relationship between the microstructure and crack. So this study can provide a theoretical reference for the production of a normalized pipeline steel with excellent resistance to HIC.

\section{Experiment procedure}

\subsection{Materials}

The material studied in this research was industrially produced normalized BNS pipeline steel plate which was processed by normalizing after TMCP. The thickness of the plate was $20.62 \mathrm{~mm}$ and the chemical compositions of the steel was listed in Table 1.

Table 1. Chemical compositions of the test steel

\begin{tabular}{ccccccc}
\hline $\mathrm{C}$ & $\mathrm{Si}$ & $\mathrm{Mn}$ & $\mathrm{P}$ & $\mathrm{S}$ & $\mathrm{V}+\mathrm{Ti}$ & $\mathrm{Ni}+\mathrm{Cr}$ \\
\hline 0.088 & 0.2 & 1.0 & 0.008 & 0.0005 & $\leqslant 0.08$ & $\leqslant 0.45$ \\
\hline
\end{tabular}

\subsection{Hydrogen sulfide corrosion test}

The samples of the hydrogen sulfide corrosion test were cut along the ND-RD section and the test was based on the standard of the NACE TM0284-2016. According to the standard, the A solution was adopted, with $\mathrm{PH}=2.8$, and the samples were placed in a sealed container at room temperature $\left(25 \pm 3^{\circ} \mathrm{C}\right)$, atmospheric pressure, with saturated $\mathrm{H}_{2} \mathrm{~S}$ gas accessing for 96 hours. Then the samples were removed and cut for observation according to the standard. Crack Sensitivity Ration(CSR), Crack

* Corresponding author: zhanghai1861@ $163 . c o m$ 
Length Ration(CLR), and Crack Thickness Ration(CTR) of the samples were measured and calculated using the following equations.

$$
\begin{aligned}
& \mathrm{CSR}=\frac{\sum(a \times b)}{W \times T} \times 100 \% \\
& \mathrm{CLR}=\frac{\sum a}{W} \times 100 \% \\
& \mathrm{CTR}=\frac{\sum b}{\mathrm{~T}} \times 100 \%
\end{aligned}
$$

In the equation, $a$ is the length of crack generated on the sample, $b$ is the width of crack generated on the sample, $\mathrm{T}$ is the thickness of sample and $\mathrm{W}$ is the width of sample.

\subsection{Microstructure and hydrogen induced crack analysis}

The samples that had been conducted for measurement for HIC were etched slightly with $4 \%$ nital solution. Then the microstructure of the samples and the hydrogen induced crack generated on the samples were observed using OM and HITACHI S-3400N SEM.

\section{Results and discussion}

The HIC sensitivity of material is usually characterized by CSR, CLR, CTR. According to the standard above, when the $\mathrm{CSR} \leq 2 \%, \mathrm{CLR} \leq 15 \%$, and $\mathrm{CTR} \leq 5 \%$, the material is not sensitive to HIC. The average values of the CSR, CLR, and CTR of the samples measured by the test for HIC were $0.43 \%, 34.72 \%$, and $2.77 \%$ respectively, so the samples have poor HIC resistance.
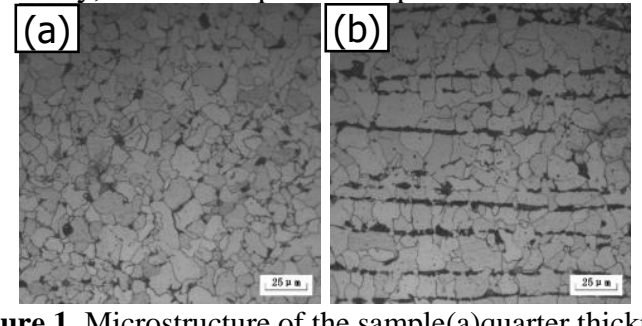

Figure 1. Microstructure of the sample(a)quarter thickness (b)center

The microstructure of the quarter thickness and center of the sample was shown in Figure 1. Figure 1 shows that the microstructure of the sample is a mixture of ferrite and pearlite and there are long strips of pearlite band structure in the center of sample but with no pearlite band structure in the quarter thickness of sample. The morphology of the hydrogen induced cracks generated on the sample was shown in Figure 2. Figure 2 shows the cracks produced are clear and long-size, and their shape is approximately linear. The cracks mainly distribute near the pearlite band generated at the center of the sample, and the crack propagation path almost coincides with the pearlite band, as is shown by the arrow in Figure 2(b). The crack at the box in Figure 2(a) was observed at a higher multiple under SEM and the result was shown in Figure 2(c). The Figure 2(c) shows that the long-size and linear shape crack propagates transgranularly.
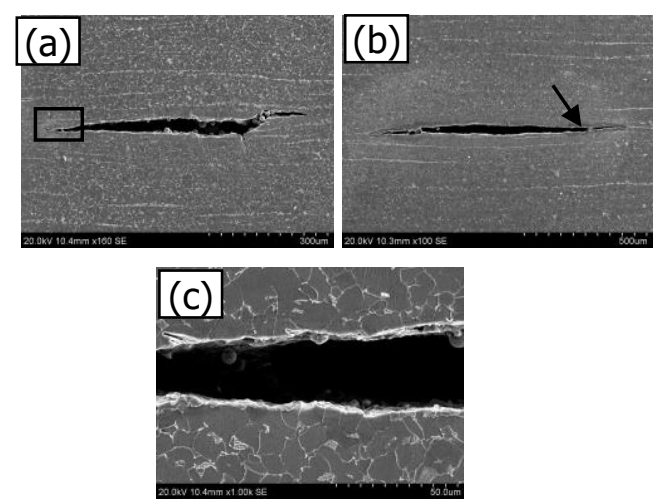

Figure 2. Morphology of the hydrogen induced cracks generated on samples

It is well-accepted that the hydrogen induced crack in pipeline steel is easy to initiate at the central segregation band and extend along the segregation band ${ }^{[5-8]}$. Therefore, the SHIMADZU EPMA-1720 electron probe microanalyzer was used to analyze the element segregation at the center of the sample and the element segregation near the long-size crack. The electron probe analysis result was shown in Figure 3 and Figure 4. There are obvious positive segregation of $\mathrm{C}$ and $\mathrm{Mn}$ at the center of the sample, and the $\mathrm{C}$ segregation bands and $\mathrm{Mn}$ segregation bands are basically coincided with the pearlite bands, as is shown in Figure 3(a) and (b). So the segregation of $\mathrm{C}$ and $\mathrm{Mn}$ leads to the formation of pearlite band in the center of sample. There is no sulfur segregation and phosphorus segregation at the center of the sample which are easy to segregate, as is shown in Figure 3(c) and (d). It has been reported in some document $\mathrm{s}^{[7,9]}$ that carbonitride precipitation of niobium, titanium, and vanadium was observed inside the band structure region and these carbonitride precipitation was considered to aggravate the negative effect of the band structure. And the band structure containing carbonitride precipitation was more likely to induce crack. However, in this investigation, there is neither obvious vanadium segregation and titanium segregation at the center of sample nor the aggregation of precipitation of vanadium and titanium in the band structure region, as illustrated by Figure 3(e) and (f).
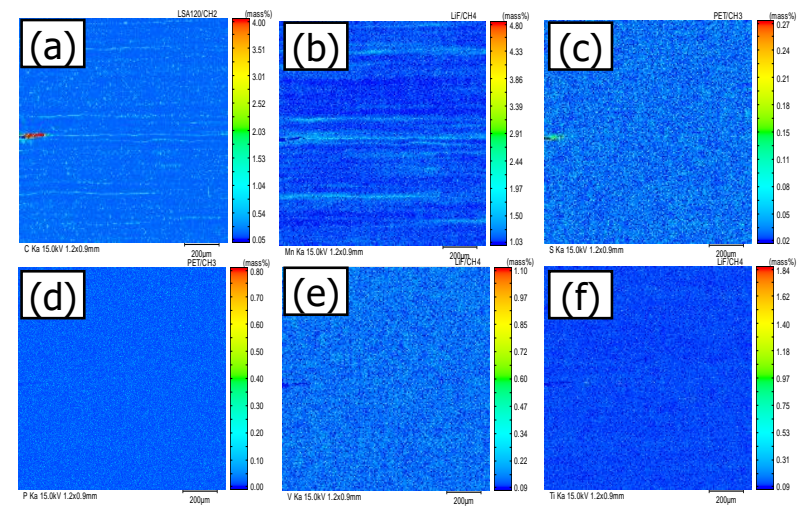

Figure 3. Electron probe analysis result of element segregation in the center of the sample(a) C (b) Mn (c) S (d) P (e) V (f) Ti

Figure 4 shows the element segregation near the crack. As is shown in the Figure 4, the long-size and linear shape crack generates at the pearlite band structure 
where $\mathrm{C}$ and $\mathrm{Mn}$ segregate. While the crack almost extends along the pearlite band.
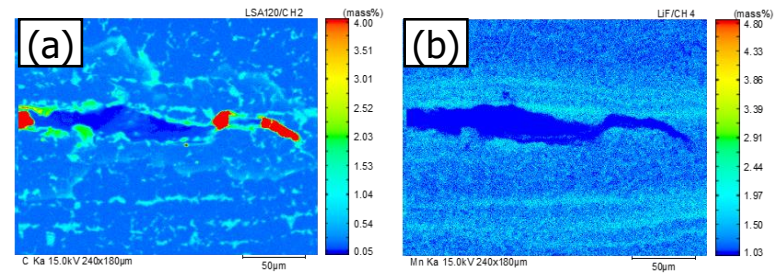

Figure 4. Electron probe analysis result of element segregation near the $\operatorname{crack}(\mathrm{a}) \mathrm{C}$ (b) Mn

It was pointed out that the origin of the hydrogen induced crack is related to the hard phase in the microstructure ${ }^{[7,10-12]}$. Therefore, the microhardness(HV0.1) test was performed on the pearlite band near the crack and the region $100 \mu \mathrm{m}$ distance away from the pearlite band. And 15 points were tested for both regions, and the test result was shown in Figure 5. The maximum value of microhardness of the pearlite band is 198HV0.1 and the mean value is 169 HV0.1. Meanwhile the maximum value of microhardness of the region $100 \mu \mathrm{m}$ distance away from the pearlite band is $146 \mathrm{HV} 0.1$ and the mean value is $135 \mathrm{HV0.1}$, as is shown in Figure 5. So the microhardness of the pearlite band was obviously higher than this of the region $100 \mu \mathrm{m}$ away from the pearlite band.

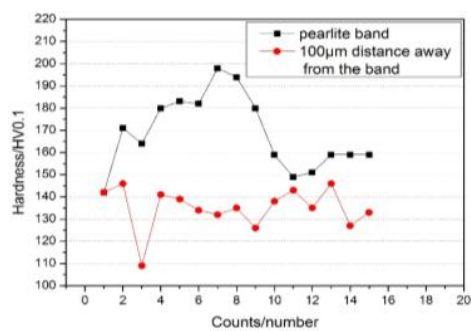

Figure 5. Microhardness test result

Aside the long-size and linear shape crack at the center of the sample thickness, there were some tiny cracks generated on the sample, as is shown in Figure 6(a). Figure 6(b) shows the energy spectral analysis result of the tiny crack zone, and small size granular calcium-aluminate inclusion was discovered inside the crack. It is well accepted that as a major hydrogen trap, inclusions can cause hydrogen induced $\operatorname{crack}^{[13-16]}$. So the tiny crack here should be hydrogen induced crack that nucleated from small calcium-aluminate inclusion, but it doesn't extend further. So the hydrogen induced crack originated from the small calcium-aluminate inclusion would not propagate to form long-size crack if there is no suitable crack propagation path for it.

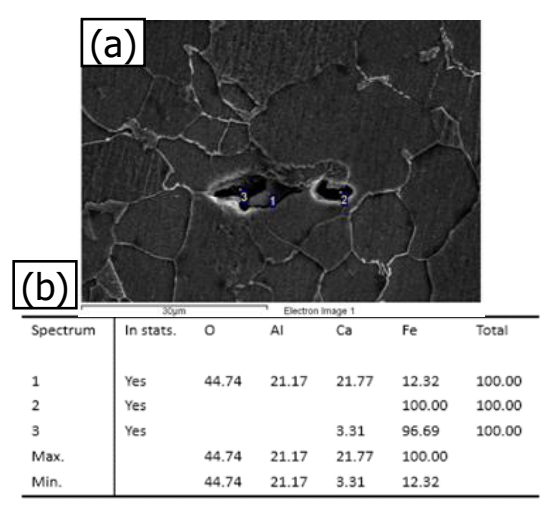

Figure 6. (a)SEM photograph of the tiny crack (b) energy spectral analysis of the tiny crack zone

Based on the above analysis, for the normalized BNS pipeline steel studied in this investigation, the long-size and linear shape crack at the center of the sample thickness originates from the high hardness pearlite band structure caused by the central segregation of $\mathrm{C}$ and $\mathrm{Mn}$, and the crack would extend along the pearlite band. In addition, there are also some tiny cracks nucleated from the small inclusions. Because the microstructure around these tiny cracks is homogeneous ferrite and pearlite without pearlite band, the tiny crack can't extend to form long-size crack.

\section{Conclusions}

1. For the normalized BNS pipeline steel, the high hardness pearlite band structure is caused by the center segregation of $\mathrm{C}$ and $\mathrm{Mn}$. The long-size and linear shape hydrogen induced crack at the center of plate thickness originates from this high hardness pearlite band structure and propagate along the pearlite band, and the crack propagates transgranularly.

2 . The tiny hydrogen induced crack nucleates from calcium-aluminate inclusion. When there is no suitable crack propagation path around the inclusion, the tiny crack will not propagate to form long-size crack.

3. There are no center segregation of $\mathrm{V}$ and $\mathrm{Ti}$, and the aggregation of precipitates of vanadium and titanium in the band structure region at the center of plate thickness.

\section{References}

1. J. Cheng, J. Liu, F. Huang, et al. Hydrogen-induced Cracking Behavior of Bainite Pipeline Steel[J]. Corrosion and Protection, 2010, 31(11): 833-836.

2. Y. Zhang, Q. Cai, G. Xie. Influence of Microstructure on HIC-resistance in $\mathrm{H}_{2} \mathrm{~S}$ Containing Solutions of High Strength Pipeline Steel X65X70[J].Corrosion Science and Protection Technology, 2007, 19(6): 406-409.

3. Gyu Tae Park, Sung Ung Koh. Hwan Gyo Jung. Effect of Microstructure on the Hydrogen Efficiency and Hy-drogen Induced Cracking of Linepipe Steel[J]. Corrosion Science, 2008, 50: 1866-1871. 
4. X. Peng, J. Liu, F. Huang, et al. Effect of Microstructure on Hydrogen-induced Cracking Propagation and Hydrogen Trapping Efficiency of Pipeline Steel[J]. Corrosion and Protection, 2013, 34(10): 882-885.

5. C. Yin, X. Lan, C. Huo. Discussion on Factors Affecting Anti-HIC in Oil and Gas Pipeline[J]. Welded Pipe and Tube, 2002, 25(5) : 20-24.

6. Q. Zhou. Analysis on Stepwise HIC of Pipeline Steel in Aqueous $\mathrm{H}_{2} \mathrm{~S}$ Solutions[J]. Heat Treatment of Metals, 2004, 29(3) : 52-57.

7. J. Cheng, B. Wang, L. Hu, et al. Effect of Segregation on Hydrogen Induced Crack Properties of X65 Pipeline Steel[J]. Transactions of Materials and Heat Treatment, 2015, 36(4) : 126-132.

8. Y. Li, Z. Du, L. Sun, et al. Resistance to HIC of High Grade Pipeline Steel[J]. Journal of Iron and Steel Reasearch, 2008, 20(12) : 50-54.

9. Serna. S, Campillo. B, Albarran. J L. Crack Growth in Microalloyed Pipeline Steel for Sour Gas Transport[J]. Journal of Materials Engineering and Performance, 2005, 14(2) : 224-228.

10. Q. Zhang, C. Zhang, L. Zhang. Effect of Heat Treatment on Hydrogen-induced Cracking Resistance of X65 Pipeline Steel[J]. Heat Treatment of Metals, 2016, 41(11) : 123-128.

11. C. Zhang, L. Zhang. Effect of Composition and Process of Microstructure and Properties for X65 HIC-resistance Pipeline Steel[J]. Baosteel Technology, 2015, $2: 23-26$.

12. Al. Mansour, Alfantazi A M, EI-boujdaini M. Sulfide Stress Cracking Resistance of API-X100 High Strength Low Alloy Steel[J]. Materials \& Design, 2009, 30(10) : 4088-4094.

13. Q. Zhou, G. Ji, J. Zhang, et al. The Effect of Sulfides on Hydrogen-induced Cracking of PipeLine Steel $[\mathrm{J}]$. Journal of Materials Engineering, 2002(9):37-39.

14. F Zhen, J Liu, F Huang, et al. Effect of the Nonmetallic inclusions on the HIC Behavior of X120 Pipeline Steel[J]. Journal of Chinese Society for Corrosion and Protection, 2010, 30(2) : 145-149.

15. F. Huang, J. Liu, Z. Deng, et al. Effect of Microstructure and Inclusions on Hydrogen Induced Cracking Susceptibility and Hydrogen Trapping Efficiency of X120 Pipeline Steels[J]. Materials Science and Engineering A, 2010, 527(26) : 69972001.

16. Elboujdaini M, Shehata M T, Sastri V S, et al. Hydrogen Induced Cracking and Effect of NonMetallic Inclusions in Linepipe Steel[J]. Corrosion, 1987(9): 748. 